\title{
Laccase produced by a thermotolerant strain of Trametes trogii LK13
}

\author{
Jinping Yan ${ }^{1}$, Yuhui Chen ${ }^{2}$, Jiezhen Niu ${ }^{1}$, Daidi Chen ${ }^{1}$, Irbis Chagan ${ }^{1}$ \\ ${ }^{1}$ Biotechnology Research Center of Life Science and Technology College, \\ Kunming University of Science and Technology, Kunming Yunnan, PR China. \\ ${ }^{2}$ College of Life Science, The Southwest Forest University, Kunming Yunnan, PR China.
}

Submitted: August 18, 2013; Approved: June 6, 2014

\begin{abstract}
Thermophilic and thermotolerant micro-organisms strains have served as the natural source of industrially relevant and thermostable enzymes. Although some strains of the Trametes genus are thermotolerant, few Trametes strains were studied at the temperature above $30^{\circ} \mathrm{C}$ until now. In this paper, the laccase activity and the mycelial growth rate for Trametes trogii LK13 are superior at $37^{\circ} \mathrm{C}$. Thermostability and organic cosolvent tolerance assays of the laccase produced at $37^{\circ} \mathrm{C}$ indicated that the enzyme possessed fair thermostability with $50 \%$ of its initial activity at $80^{\circ} \mathrm{C}$ for $5 \mathrm{~min}$, and could remain 50\% enzyme activity treated with organic cosolvent at the concentration range of $25 \%-50 \%(\mathrm{v} / \mathrm{v})$. Furthermore, the test on production of laccase and lignocellulolytic enzymes showed the crude enzymes possessed high laccase level $\left(1000 \mathrm{U} \mathrm{g}^{-1}\right)$ along with low cellulose $\left(2 \mathrm{U} \mathrm{g}^{-1}\right)$ and xylanase $\left(140 \mathrm{U} \mathrm{g}^{-1}\right)$ activity. Thus, T. trogii LK13 is a potential strain to be applied in many biotechnological processes.
\end{abstract}

Key words: Trametes trogii, thermotolerant fungi, Laccase, thermostability, organic cosolvent tolerance.

\section{Introduction}

To degrade lignocelluloses materials, filamentous fungi produce complex extra- and intracellular enzyme systems which include cellulose, xylan and lignin oxidation enzymes (Abdel-Hamid et al., 2013). Laccase (EC 1.10.3.2, Lac) is one of the most important lignin oxidation enzymes that can non-specifically degrade many phenolic and non-phenolic compounds, such as lignin and many environmental pollutants (including synthetic dyes, toxic substances in industrial effluents, herbicides and pesticides in soil) (Rodríguez Couto and Toca Herrera, 2006). Due to the ability to degrade and detoxify many environmental pollutants, laccases have been widely applied in several biotechnological processes (Rodgers et al., 2009).

Laccases and laccase-like proteins have been described in plants, arthropods, bacteria and bovine rumen microflora, with particular emphasis on the fungi, especially in the white rot basidiomycetes (Beloqui et al., 2006; Claus, 2004). In order to facilitate novel and more efficient bio-catalytic applications at industrial scale, the biochemi- cal and financial properties of fungi laccase must be improved (Hildén et al., 2009; Piscitelli et al., 2011). Many biochemical properties of laccases closely related to their application, including thermostability, thermotolerance, pH-stability, organic solvent-tolerant (Huang et al., 2011) and high salts-tolerance (Ellouze et al., 2010; Hildén et al., 2009).

Thermophilic and thermotolerant micro-organisms strains have served as the natural source of industrially relevant and thermostable enzymes (Boonlue et al., 2003). Moreover, the thermostable enzymes usually have higher resistance to chemical denaturants, high alkalinity and extreme acidity (Hildén et al., 2009). Currently, thermostable fungi laccases in industrial application are mainly isolated from Melanocarpus albomyces, Myceliophtora thermophila and Chaetomium thermophilum, which all belong to the Ascomycota (Hildén et al., 2009).

As a potential white rot basidiomycete source of thermostable laccases, the Trametes strains have attracted much attention, such as T. versicolor, T. pubescens and $T$. 
trogii. These strains can produce unique extra-cellular oxidative enzymes, including $\mathrm{Mn}$-peroxidase $(\mathrm{MnP})$ and laccase, and the latter is the dominant one. It has been reported that many laccase isozymes from this genus show exceptionally high thermal stability (Hildén et al., 2009). Interestingly, elevating the temperature of the enzyme production or heat shock treatment can improve laccase production in the strains of the Trametes genus (Tong et al., 2007; Wang et al., 2012). Thus, the Trametes genus is considered to be the potential source of novel and thermostable laccases (Hildén et al., 2009).

It is worth pointing out that $T$. trogii is a thermotolerant species preferring sun-exposed habitats, but until now, few related studies of $T$. trogii were conducted over $30{ }^{\circ} \mathrm{C}$, mostly at 28 or $30^{\circ} \mathrm{C}$ (Mutlu et al., 2010). In this study, laccase produced by the newly isolated thermotolerant $T$. trogii strain LK13 was investigated at $37^{\circ} \mathrm{C}$.

\section{Materials and Methods}

\section{Isolation and identification of strain}

The fungal fruit body growing on the decayed wood was collected from the forest in Lijiang, China. After the elimination of surface contamination, the fragments (approximately $5 \mathrm{~mm}^{2}$ ) of the fruit body were placed on $2 \%$ MA (malt extract agar) plate for incubation at $28{ }^{\circ} \mathrm{C}$. The pure cultures were obtained from hyphal tip. Morphological characteristics of the fungal fruit body and mycelia were observed by Micro- and Macro- scope. Molecular identification is performed based on a modified protocol. In brief, total genomic DNA was extracted from the 6-day fresh mycelium using the CTAB method, and the ITS region was amplified using the primer pairs: 5'-GGAAGTAAAAGTCGTAACAAGG-3' (forward) and 5'-TCCTCCGCTTATTGATATGC-3' (reverse). The amplification was performed as follow: 1 cycle of $94^{\circ} \mathrm{C}$ for $1 \mathrm{~min} ; 30 \mathrm{~s}$ at $94{ }^{\circ} \mathrm{C}, 30 \mathrm{~s}$ at $55^{\circ} \mathrm{C}$ and $30 \mathrm{~s}$ at $72{ }^{\circ} \mathrm{C}$ for 26 cycles; followed by a final extension of $10 \mathrm{~min}$ at $72^{\circ} \mathrm{C}$. Phylogenetic analysis and construction of an unrooted tree were performed by the software MEGA version 3.0.

\section{Growth characteristics at different temperatures}

To explore the optimal growth temperature of strain, 4-day-old mycelial blocks in the diameter of $5 \mathrm{~mm}$ incubated at $28{ }^{\circ} \mathrm{C}$ were transferred to the $2 \%$ MA plates kept at different temperatures (including $28{ }^{\circ} \mathrm{C}, 30{ }^{\circ} \mathrm{C}, 34^{\circ} \mathrm{C}$, $37^{\circ} \mathrm{C}, 40{ }^{\circ} \mathrm{C}$ and $42{ }^{\circ} \mathrm{C}$ ). The growth rate of the colonies was recorded and the features of clonies were also observed.

\section{Localisation of laccase activity by staining}

Localisation of laccase activity was determined according to the method of Hiscox et al. (2010). Mycelial block with a diameter of $5 \mathrm{~mm}$ from the $2 \%$ MA plate was transferred to $9 \mathrm{~cm}$ Petri dishes plus $250 \mathrm{mg} \mathrm{L}^{-1} 2,2^{\prime}$-azino bis (3-ethylbenzthiazoline-6- sulphonic acid) (ABTS, Sigma, USA), and the green/violet zone was recorded at $2 \mathrm{~d}, 8 \mathrm{~d}, 15 \mathrm{~d}, 1$ month and 2 months respectively.

\section{Effects of temperature and organic solvents on laccase activity}

The mycelia from the slant were transferred to the GYP plates (Fan et al., 2011) and incubated at $30^{\circ} \mathrm{C}$ for $5 \mathrm{~d}$. Inocula were prepared in $250 \mathrm{~mL}$ Erlenmeyer flask containing $50 \mathrm{~mL}$ of GYP starting from 4 mycelial plugs $(1 \mathrm{~cm}$ in diameter). Cultures grow for 5 days at $30{ }^{\circ} \mathrm{C}$ were homogenized by beaded glasses ( $0.3 \mathrm{~mm}$ in diameter), and $5 \%(\mathrm{v} / \mathrm{v})$ aliquots of the mycelia suspension were used as inocula for laccase production. The supernatants of 9-day-old liquid culture of $T$. trogii LK13 were obtained by centrifugation (9 $000 \mathrm{rpm}, 5 \mathrm{~min}$ at $\left.4{ }^{\circ} \mathrm{C}\right)$, and the crude enzyme solutions were used for the further study.

To determine the effect of temperature on laccase activity, the laccase was incubated at a temperature range of $20-85^{\circ} \mathrm{C}$ in phosphate citrate buffer $(100 \mathrm{mM}, \mathrm{pH} 4.0)$ for $5 \mathrm{~min}$ and then the residual laccase activity was determined at room temperature. To further determine the half-life at certain temperature, the residual laccase activity was determined after the crude enzyme solutions were incubated at given temperature in phosphate citrate buffer (100 mM, pH 4.0) with different time intervals. To determine the effect of organic solvents on laccase activity, the reaction mixture was added with methanol, isopropanol, acetonitrile, acetone, formalin or DMSO to get the final concentration. The laccase activity of the reaction mixture without organic solvent was recorded as $100 \%$.

\section{Solid state fermentation (SSF)}

Rice straw, bagasse, sawdust, cotton seed coat fragments were obtained in the region of Kunming city. After dried at $80^{\circ} \mathrm{C}$ for 4 days, the lignocellulosic materials were milled by a micro-grinder. Through the sieve screen, $1 \mathrm{~mm}$ chips were used for the solid state fermentation, which employed $5 \mathrm{~g}$ materials in $16 \mathrm{~mL}$ culture solution (peptone, $12.5 \mathrm{~g} \mathrm{~L}^{-1}$; malt extract, $30 \mathrm{~g} \mathrm{~L}^{-1}$ and $11 \mathrm{mM} \mathrm{CuSO}_{4}$ ) according to the study by Levin et al. (2008). The substrates were inoculated with 4 mycelial blocks in a diameter of $1 \mathrm{~cm}$ in a $250 \mathrm{~mL}$ Erlenmeyer flask, and kept in darkness at $37^{\circ} \mathrm{C}$ for 4 weeks. Crude enzyme was obtained by adding $0.05 \mathrm{M}$ sodium acetate buffer ( $\mathrm{pH} 4.8$ ) to the fermented culture at a liquor ratio of 1:10. Subsequently, the mixture was stirred continuously at $200 \mathrm{rpm}$ for $30 \mathrm{~min}$ and centrifugated at $10000 \mathrm{rpm}$ for $10 \mathrm{~min}$ at $4{ }^{\circ} \mathrm{C}$. The supernatants were used for the enzyme activity assay.

\section{Enzyme assays}

Laccase activity was routinely determined with ABTS $\left(\varepsilon_{420}=36(\mathrm{mM} \mathrm{cm})^{-1}\right)$ as substrate. Mixture of $0.5 \mathrm{~mL}$ appropriately diluted crude enzyme and $1.1 \mathrm{~mL}$ of $2 \mathrm{mM}$ ABTS in phosphate citrate buffer (100 mM, pH 4.0) 
was used to determine the activity. The increase in absorbance was monitored at $420 \mathrm{~nm}$ for $3 \mathrm{~min}$ (Bourbonnais and Michael, 1990). One unit of the enzyme activity was defined as the amount of the enzyme that oxidized $1 \mu \mathrm{mol}$ of the ABTS per minute. MnP activity (E.C:1.11.1.13) was measured using phenol red as the substrate in $0.1 \mathrm{M}$ sodium dimethylsuccinate buffer $(\mathrm{pH} 4.5)$ at room temperature $\left(\varepsilon_{610}=22\left(\mathrm{mM} \mathrm{cm}^{-1}\right)(\right.$ Glenn and Gold, 1985). Organic solvent tolerance and the thermal stability assays were preformed according to the methods of Farnet et al. (2008) and Halaburgi et al. (2011), respectively. Exo- $\beta$-D-1, 4-glucanase and endo- $\beta$-D-1, 4-xylanase activities were determined according to the method of Levin et al. (2008).

\section{Results}

\section{Microorganism identification}

Based on the characteristics of fruity body (Figure 1a) and microscopy observation of hyphae (Figure 1b) combined with the ITS rDNA gene sequence with the $99 \%$ identity to that of most strains of $T$. trogii deposited in the Genbank database, the isolated strain LK13 was identified as T. trogii (Figure 1c). The sequence was submitted to GenBank with the accession no: JX105361.

\section{Growth characterization of $T$. trogii LK13 strain at different temperatures}

Colonies of $T$. trogii LK13 strain could typically grow at $28-42{ }^{\circ} \mathrm{C}$ on $2 \%$ MA plate (Figure 2), but the optimal temperature range was $34-37^{\circ} \mathrm{C}$. Mycelium rapidly expanded to the margin of $9 \mathrm{~cm}$ Petri dishes within 4 days at $37^{\circ} \mathrm{C}$, while 8 days were needed at $28^{\circ} \mathrm{C}$ to cover the same size. Mycelium even could grow at $42^{\circ} \mathrm{C}$ (Figure 2), which was the lethal temperature for most filamentous fungi.

\section{Location of laccase activity by staining}

To study the laccase production of $T$. trogii LK13 at different temperatures, in situ staining method of enzyme activity was employed. After the culture for 6 days at $37^{\circ} \mathrm{C}$, a clear green zone with the average diameter of $4 \mathrm{~cm}$ was observed around the inoculum block on the plate of MA with $250 \mathrm{mg} \mathrm{L}^{-1}$ ABTS (Figure 3b), and the next 4 days, the green zone expanded to the margin of the dish and simultaneously was turn into strong violet (Figure 3c). While only light orange was observed on Petri dishes with ABTS at $28{ }^{\circ} \mathrm{C}$ even more than 12 days of cultivation (Figure $3 \mathrm{e}$ ). Based on these observations, T. trogii LK13 should produce the laccase at both $28{ }^{\circ} \mathrm{C}$ and $37^{\circ} \mathrm{C}$, and the activity was higher at $37^{\circ} \mathrm{C}$.

\section{Effect of temperature and organic solvents on laccase activity}

There was almost no loss of activity at $45{ }^{\circ} \mathrm{C}$ and $55^{\circ} \mathrm{C}$ (Table 1). With the temperatures increasing to $65^{\circ} \mathrm{C}$, $70{ }^{\circ} \mathrm{C}$ and $75{ }^{\circ} \mathrm{C}$, about $11.3 \%, 15.9 \%$ and $22.4 \%$ laccase activities were reduced (Table 1). The enzyme retained about $50 \%$ its initial activity at $80{ }^{\circ} \mathrm{C}$, while only $5 \%$ activity was remained at $85{ }^{\circ} \mathrm{C}$ (Table 1). In addition, the enzyme retained $72.3 \%$ and $35.5 \%$ of its initial activity at $75^{\circ} \mathrm{C}$ for $10 \mathrm{~min}$ and $30 \mathrm{~min}$, respectively.

Among all tested organic solvents, $10 \%(\mathrm{v} / \mathrm{v})$ isopropanol and acetonitrile increased the laccase activity by about $21 \%$ and $25 \%$ respectively, while the activity slightly declined to $86.9 \%$ and $99.2 \%$ of the control with the concentration reaching to $20 \%$ (v/v) (Table 2). DMSO obviously inhibited the laccase, and $5 \%(\mathrm{v} / \mathrm{v})$ regent could lead to the $41.3 \%$ loss of activity (Table 2 ). The inhibiting concentration where $50 \%$ of laccase activity remained was about $40 \%(\mathrm{v} / \mathrm{v})$ for methanol, about $25 \%(\mathrm{v} / \mathrm{v})$ for acetone and formalin (Table 2).

\section{Production of laccase using solid state fermentation (SSF)}

The substrates of rice straw, bagasse, sawdust, cotton seed coat fragments were completely colonized within 7, 9, 4 and 4 days, respectively. Compared with rice straw, all other materials could lead to the fast mycelium-growth and high laccase activity (Table 3 ). On the culture with cotton seed coat fragments, the activity gradually increased from day 3 and achieved the maximal values of about $1263 \mathrm{U} \mathrm{g}^{-1}$ at day 7 (Table 3).

At the same time, the laccase activity reached about 800,400 and $1000 \mathrm{U} \mathrm{g}^{-1}$ on rice straw, bagasse and sawdust, respectively (Table 3 ), and they showed the highest activity at day 14 , which were still lower than that in cotton seed coat fragments culture. During the whole fermentation cycle, Exo- $\beta$-D-1, 4-glucanase activity was always lower than $2.3 \mathrm{U} \mathrm{g}^{-1}$, and even on rice straw culture which was cellulose-rich lignocellulosic substrate. The lowest Exo- $\beta$-D-1, 4-glucanase activity was present in cotton seed coat fragments culture with the values of about $1 \mathrm{Ug}^{-1}$ on day 7 (Table 3), and extracellular xylanase maintained the activity of 255.6 $\mathrm{U} \mathrm{g}^{-1}$ (Table 3).

\section{Discussion}

Due to harsh industrial process conditions that may include high temperature and/or pressure, high salt concentrations, acidic or alkaline $\mathrm{pH}$, oxidative conditions, high shear forces or short delays, resistant enzymes are required (Hildén et al., 2009). Previous studies have demonstrated that the thermostable enzymes usually are higher resistant to chemical denaturants, high alkalinity and extreme acidity (Hildén et al., 2009). Thermophilic and thermotolerant micro-organisms strains have served as the natural source of industrially relevant and thermostable enzymes (Boonlue et al., 2003). Phanerochaete chrysosporium is well studied thermophilic white-rot fungus. However, $P$. chrysosporium strains mainly produce lignin peroxidase (LiP) and manganese-dependent peroxidase (MnP), not 

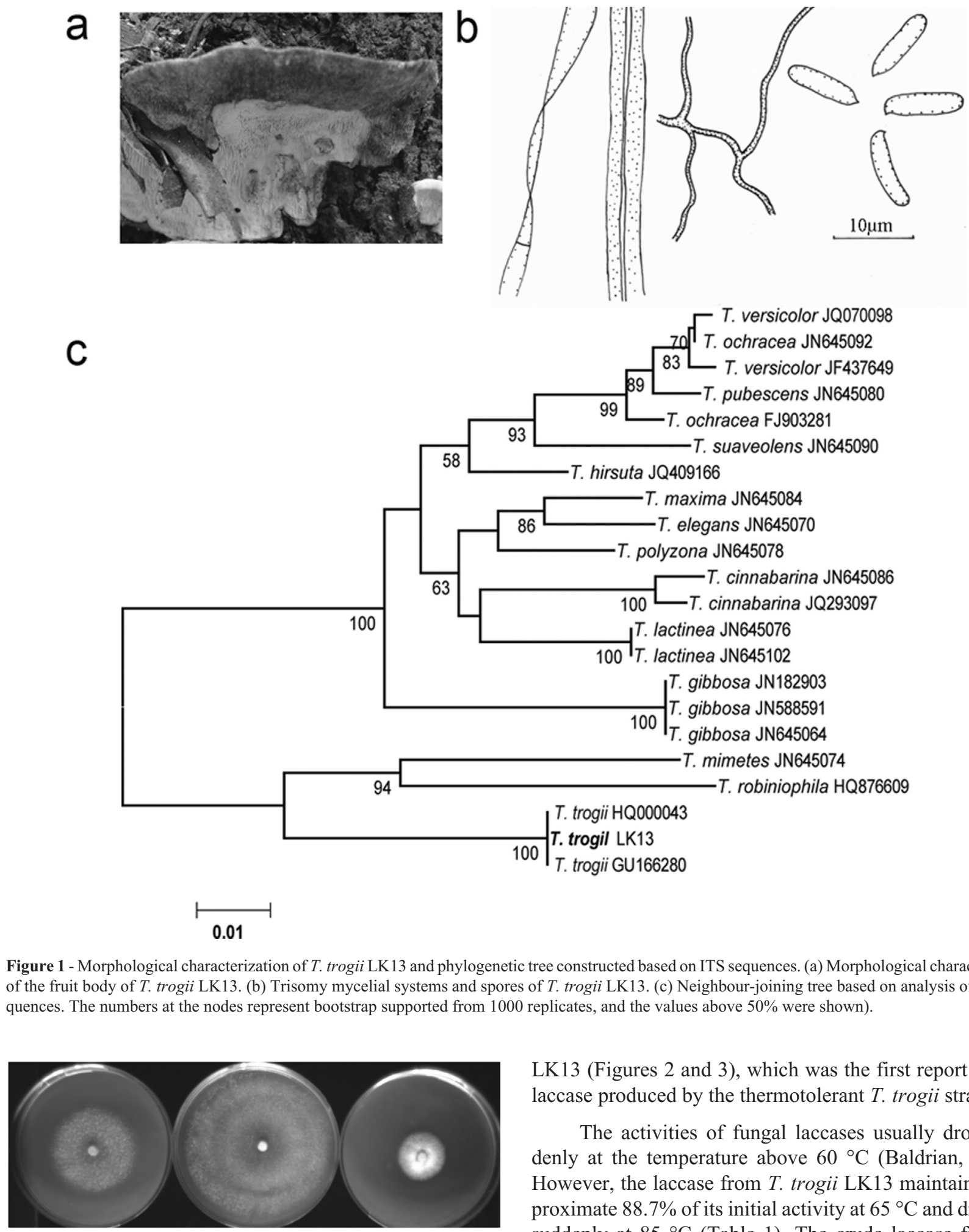

89

T. versicolor JQ070098

T. ochracea JN645092

— T. versicolor JF437649

T. pubescens JN645080

93

99

T. ochracea FJ903281

T. suaveolens JN645090

T. hirsuta JQ409166

T. maxima JN645084

86 -T. elegans JN645070

-T. polyzona JN645078

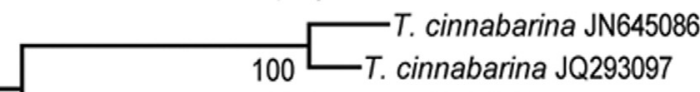

T. lactinea JN645076

100 T. lactinea JN645102

100 T. gibbosa JN588591

T. gibbosa JN645064

-T. mimetes JN645074

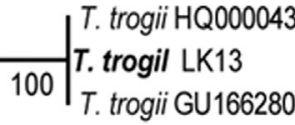

T. robiniophila HQ876609

of the fruit body of $T$ trogii LK13. (b) Trisomy mycelial systems and spores of $T$ trogii LK13. (c) Neighbour-joining tree based on analysis of ITS sequences. The numbers at the nodes represent bootstrap supported from 1000 replicates, and the values above $50 \%$ were shown).

Figure 2 - Comparison of the mycelial growth rate of $T$. trogii LK13 strain under different temperatures. After the culture for 4 days under $28{ }^{\circ} \mathrm{C}$ (Left), $37{ }^{\circ} \mathrm{C}$ (Middle) and $42{ }^{\circ} \mathrm{C}$ (Right) on $2 \%$ MA.

laccase (Abdel-Hamid et al., 2013). Our study certified that the optimal temperature of $37^{\circ} \mathrm{C}$ was for both mycelium growth and laccase production in a newly isolated $T$. trogii
LK13 (Figures 2 and 3), which was the first report on the laccase produced by the thermotolerant $T$. trogii strain.

The activities of fungal laccases usually drop suddenly at the temperature above $60{ }^{\circ} \mathrm{C}$ (Baldrian, 2006). However, the laccase from $T$. trogii LK13 maintained approximate $88.7 \%$ of its initial activity at $65^{\circ} \mathrm{C}$ and dropped suddenly at $85{ }^{\circ} \mathrm{C}$ (Table 1). The crude laccase from $T$. trogii LK13 retained $84.1 \%$ and $77.6 \%$ of its initial activity after the incubation at $70{ }^{\circ} \mathrm{C}$ and $75^{\circ} \mathrm{C}$ for $5 \mathrm{~min}$ respectively, which is higher than the laccase from Cladosporium cladosporioides and T. hirsuta (Halaburgi et al., 2011; Zhang et al., 2009). The $\mathrm{T}_{50}$ of the crude laccase from T. trogii LK13 (defined as the temperature at which the enzyme retains $50 \%$ of its initial activity) at $70{ }^{\circ} \mathrm{C}$ and $75^{\circ} \mathrm{C}$ 


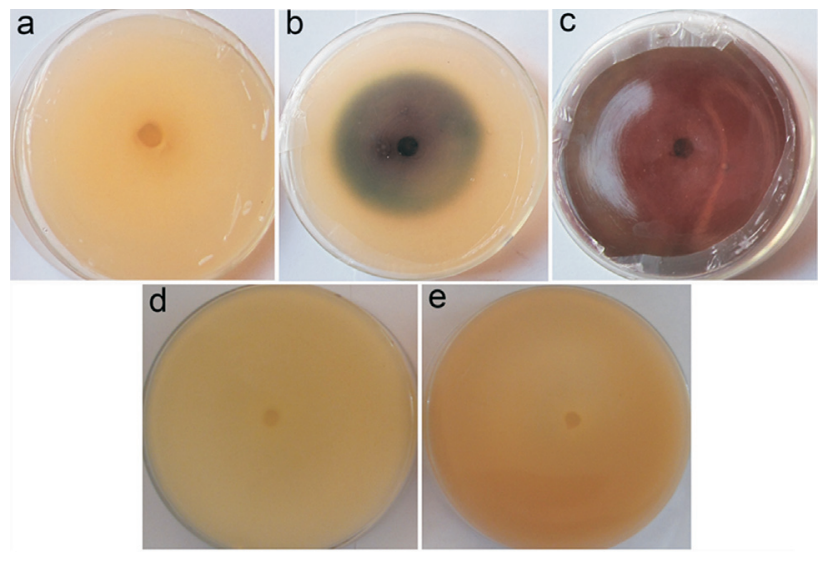

Figure 3 - Localisation of the laccase activity of T. trogii LK13 strain using in situ staining method. Laccase production under $37^{\circ} \mathrm{C}$ at day 6 (b) and day 10 (c), and $28^{\circ} \mathrm{C}$ (e) on $2 \%$ MA added with $250 \mathrm{mg} \mathrm{L}^{-1} \mathrm{ABTS}$. (a) and (d) on $2 \%$ MA without ABTS as the control for $37^{\circ} \mathrm{C}$ and $28{ }^{\circ} \mathrm{C}$, respectively. Laccase with high activity can generate a purple or green zone.

Table 1 - The stability of the crude laccase from T. trogii LK13 under different temperatures.

\begin{tabular}{lc}
\hline Temperature $\left({ }^{\circ} \mathrm{C}\right)$ & Remaining activity $(\%)$ \\
\hline 0 & 100 \\
45 & $100 \pm 0.5$ \\
55 & $92.7 \pm 3.9$ \\
65 & $88.7 \pm 4.6$ \\
70 & $84.1 \pm 8.2$ \\
75 & $77.6 \pm 2.2$ \\
80 & $53.5 \pm 7.6$ \\
85 & $5.7 \pm 0.2$ \\
\hline
\end{tabular}

was higher than that of laccases from T. hirsuta, Pleurotu cinnabarinus, P. ostreatus, Coriolopsis gallica and T. versicolor (Bommarius et al., 2006; Maté et al., 2010), while it was lower than that from Pycnoporus sanguineus (SCC 108) (Litthauer et al., 2007) and lacIII from Trametes sp. HS-03 (Guo et al., 2012). The crude laccase was used for thermostability assay in this study, which may affect the comparability of the purified laccases, but this comparability also indicates that $T$. trogii LK13 is a promising resource of laccase with fair thermostability.

Many substrates of laccases are organic pollutants which contain high concentrations of organic solvents to
Table 2 - The influence of organic solvents on the crude laccase activity from $T$. trogii LK13.

\begin{tabular}{lcc}
\hline Organic solvent & $\begin{array}{c}\text { Concentration } \\
(\%, \mathrm{v} / \mathrm{v})\end{array}$ & $\begin{array}{l}\text { Remaining } \\
\text { activity }(\%)\end{array}$ \\
\hline Control & $/$ & 100 \\
Methanol & 40 & $52.8 \pm 18.9$ \\
Isopropanol & 10 & $121.6 \pm 4.0$ \\
Acetonitrile & 20 & $86.9 \pm 5.2$ \\
& 10 & $125.3 \pm 8.3$ \\
Acetone & 20 & $99.2 \pm 17.0$ \\
Formalin & 25 & $42.2 \pm 0.6$ \\
DMSO & 25 & $55.6 \pm 6.5$ \\
\hline
\end{tabular}

enhance the solubility (Maté et al., 2010). Thus, fungal laccases with organic cosolvent tolerance can make their practical use available (Farnet et al., 2008). In Marasmius quercophilus, $50 \%$ of the laccase activity remained when ethanol, methanol and acetone were added at the concentration of $60 \%, 40 \%$ and $40 \%(\mathrm{v} / \mathrm{v})$ respectively (Farnet et al., 2008), which is superior to the crude laccase from T. trogii LK13. However, Laccase activity increased by about $21 \%$ and $25 \%$ respectively when isopropanol and acetonitrile were added at the concentration of $10 \%(\mathrm{v} / \mathrm{v})($ Table 2), while laccase of M. quercophilus didn't show the increased activity at all tested organic solvents.

Lignocellulose is the most abundant renewable biomass on earth, and it has long been recognized as an alternative source for producing renew-able fuels and chemicals (Abdel-Hamid et al., 2013). Pretreatment is a crucial step in the conversion of lignocellulosic biomass to fermentable sugars and biofuels. Using lignin-degrading microorganisms, fungal pretreatment potentially provides an environmentally-friendly and energy-efficient pretreatment technology (Wan and Li, 2012). Fungal pretreatment encounters the challenge of cellulose loss along with delignification because of the tested fungi generally with high cellulose and xylanase activities (Nakagame et al., 2006; Shi et al., 2009). Thus, cellulose-deficient white rot fungi are extremely needed (Nakagame et al., 2006; Shi et $a l ., 2009)$. In this work, some relevant hydrolytic enzymes were studied, including Exo- $\beta$-D-1, 4-glucanase and endo$\beta$-D-1, 4-xylanase. Both of them produced by strain $T$.

Table 3 - Hydrolytic and oxidative activities of solid-state fermentation materials prepared on various lignocellulose substrates for $7 \mathrm{~d}$.

\begin{tabular}{lccc}
\hline Substrate & Laccase $\left(\mathrm{U} \mathrm{g} \mathrm{g}^{-1}\right)$ & Exo- $\beta$-D-1, 4-glucanase $\left(\mathrm{U} \mathrm{g} \mathrm{g}^{-1}\right)$ & Endo- $\beta$-D-1, 4 -xylanase $\left(\mathrm{U} \mathrm{g}{ }^{-1}\right)$ \\
\hline Rice straw & $800.6 \pm 15.3$ & $2.3 \pm 0.17$ & $139.3 \pm 11.2$ \\
Bagasse & $400.3 \pm 25.6$ & $2.0 \pm 0.33$ & $140.2 \pm 13.8$ \\
Sawdust & $1000 \pm 50$ & $1.5 \pm 0.2$ & $145.6 \pm 17.0$ \\
Cotton seed coat fragments & $1263.8 \pm 34$ & $1.1 \pm 0.15$ & $158.6 \pm 15.8$ \\
\hline
\end{tabular}


trogii LK13 were detected with much lower activities than that in the strain $T$. trogii MYA 28-11 by Levin et al. (2008), and the activities of exo- $\beta$-D-1,4-glucanase and endo-oxylanase were about $2 \mathrm{U} \mathrm{g}^{-1}, 140 \mathrm{U} \mathrm{g}^{-1}$ in the strain T. trogii LK13 (Table 3) compared with that of $113 \mathrm{U} \mathrm{g}^{-1}$, $1176 \mathrm{U} \mathrm{g}^{-1}$ in $T$. trogii MYA 28-11 respectively.

In this study, the laccase activity and the mycelial growth rate for $T$. trogii $\mathrm{LK} 13$ were superior at $37^{\circ} \mathrm{C}$. The laccase produced at $37^{\circ} \mathrm{C}$ of this strain possessed good thermostability and organic cosolvent tolerance. Additionally, T. trogii LK13 could produce high laccase level $\left(1000 \mathrm{U} \mathrm{g}^{-1}\right)$ along with low Exo- $\beta-D-1,4$-glucanase and endo- $\beta$-D-1, 4-xylanase using lignocellulose materials. Thus, T. trogii LK13 is a potential strain to be applied in many biotechnological processes.

\section{Acknowledgments}

This work was supported by funds from Yunnan Provincial Science and Technology Department (Number: 2010ZC057).

\section{References}

Abdel-Hamid, AM, Solbiati JO, Cann IKO (2013) Insights into Lignin Degradation and its Potential Industrial Applications. Adv Appl Microbiol 82:1-28.

Baldrian P (2006) Fungal laccases-occurrence and properties. FEMS Microbiol Rev 30:215-242.

Beloqui A, Pita M, Polaina J, Martínez-Arias A, Golyshina OV, Zumárraga M, Yakimov MM, García-Arellano H, Alcalde M, Fernández VM, Elborough K., Andreu JM, Ballesteros A, Plou FJ, Timmis KN, Ferrer M, Golyshin PN (2006) Novel polyphenol oxidase mined from a metagenome expression library of bovine rumen: biochemical properties, structural analysis, and phylogenetic relationships. J Biol Chem 281:22933-22942.

Bommarius AS, Broering JM, Chaparro-Riggers JF, Polizzi KM (2006) High-throughput screening for enhanced protein stability. Curr Opin Biotechnol 17:606-610.

Boonlue S, Aimi T, Morinaga T (2003) Molecular characterization of a xylanase-producing thermophilic fungus isolated from Japanese soil. Curr Microbiol 47:119-124.

Bourbonnais R, Michael GP (1990) Oxidation of non-phenolic substrates: An expanded role for laccase in lignin biodegradation. FEBS Lett 267:99-102.

Claus H (2004) Laccases: structure, reactions, distribution. Micron 35:93-96.

Cruz Ramírez MG., Rivera-Ríos JM, Téllez-Jurado A (2012) Screening for thermotolerant ligninolytic fungi with laccase, lipase, and protease activity isolated in Mexico. J Environ Managet 95:S256-S259.

Ellouze ÃM, Aloui F, Sayadi S (2010) Study on the influence of high salts content on fungal treatment of saline wastewaters. Desalin Water Treat 13:411-417.

Farnet AM, Gil G, Ferre E (2008) Effects of pollutants on laccase activities of Marasmius quercophilus, a white-rot fungus isolated from a Mediterranean schlerophyllous litter. Chemosphere 70:895-900.
Fan FF, Zhuo R, Sun S, Wan X, Jiang ML, Zhang XY, Yang Y (2011) Cloning and functional analysis of a new laccase gene from Trametes sp. 48424 which had the high yield of laccase and strong ability for decolorizing different dyes. Bioresour Technol 102:3126-3137.

Galhaup C, Goller S, Peterbauer CK., Strauss J, Haltrich D (2002) Characterization of the major laccase isoenzyme from Trametes pubescens and regulation of its synthesis by metal ions. Microbiology 148:2159-2169.

Glenn JK, Gold MH, (1985) Purification and characterization of an extracellular $\mathrm{Mn}(\mathrm{II})$-dependent peroxidase from the lignin degrading basidiomycete Phanerochaete chrysosporium. Arch Biochem Biophys 242:308-329.

Guo WY, Yao ZY, Zhou CY, Li D, Chen HL, Shao Q, Li ZY, Feng HG (2012) Purification and characterization of three laccase isozymes from the white rot fungus Trametes $s p$. HS-03. Afr J Biotechnol 11:7916-7922.

Halaburgi VM, Sharma S, Sinha M, Singh TP, Karegoudar TB (2011) Purification and characterization of a thermostable laccase from the Cladosporium cladosporioides and its applications. Process Biochem 46:1146-1152.

Hildén K, Hakala TK, Lundell T (2009) Thermotolerant and thermostable laccases. Biotechnol Lett 31:1117-1128.

Hiscox J, Baldrian P, Rogers H J, Boddy L (2010) Changes in oxidative enzyme activity during interspecific mycelial interactions involving the white-rot fungus Trametes versicolor. Fungal Genet Biol 47:562-571.

Huang WT, Tai R, Hseu RS, Huang CT (2011) Overexpression and characterization of a thermostable, $\mathrm{pH}$-stable and organic solvent-tolerant Ganoderma fornicatum laccase in Pichia pastoris. Process Biochem 46:1469-1474.

Levin L, Herrmann C, Papinutti VL (2008) Optimization of lignocellulolytic enzyme production by the white-rot fungus Trametes trogii in solid-state fermentation using response surface methodology. Biochem Eng J 39:207-214.

Litthauer D, Van Vuuren MJ, Van Tonder A, Wolfaardt FW (2007) Purification and kinetics of a thermostable laccase from Pycnoporus sanguineus (SCC 108). Enzyme Microb Technol 40:563-568.

Maté D, García-Burgos C, García-Ruiz E, Ballesteros AO, Camarero S, Alcalde M (2010) Laboratory evolution of highredox potential laccases. Chem Bio 17:1030-1041.

Mutlu F, Apohan E, Kahraman S (2010) Endogenous polyamine content in the white rot fungi Coriolus (Trametes) versicolor and Funalia trogii. Fresen. Environ Bull 19:1208-1212.

Nakagame S, Furujyo A, Sugiura J (2006) Purification and Characterization of Cellobiose Dehydrogenase from White-Rot Basidiomycete Trametes hirsute. Biosci Biotech Bioch 70:1629-1635.

Piscitelli A, Giardina P, Lettera V, Pezzella C, Sannia G, Faraco V (2011) Induction and transcriptional regulation of laccases in fungi. Curr Genomics 12:104-112.

Rodgers CJ, Blanford CF, Giddens SR, Skamnioti P, Armstrong FA, Gurr SJ (2009) Designer laccases: a vogue for highpotential fungal enzymes? Trends Biotechnol 28:63-72.

Rodríguez Couto S, Toca Herrera JL (2006) Industrial and biotechnological applications of laccases: A review. Biotechnol Adv 24:500-513.

Shi J, Sharma-Shivappa RR, Chinn M, Howell N (2009) Effect of microbial pretreatment on enzymatic hydrolysis and fer- 
mentation of cotton stalks for ethanol production. Biomass Bioenerg 33:88-96.

Tong PG, Hongm YZ, Xiao YZ, Zhang M, Tu XM, Cui TJ (2007) High production of laccase by a new basidiomycete, Trametes sp. Biotechnol Lett 29:295-301.

Wan CX, Li YB (2012) Fungal pretreatment of lignocellulosic biomass. Biotechnol Adv 30:1447-1457.
Wang F, Guo C, Wei T, Zhang T, Liu CZ (2012) Heat Shock Treatment Improves Trametes versicolor Laccase Production. Appl Biochem Biotech 168:256-265.

Zhang HB, Zhang YL, Huang F, Gao PJ, Chen JC (2009) Purification and characterization of a thermostable laccase with unique oxidative characteristics from Trametes hirsute. Biotechnol Lett 31:837-843.

Associate Editor: Eduardo Cesar Ton do

All the content of the journal, except where otherwise noted, is licensed under a Creative Commons License CC BY-NC. 